\title{
Linking 1D coastal ocean modelling to environmental management: an ensemble approach
}

\author{
Giulia Mussap $^{1} \cdot$ Marco Zavatarelli $^{1}$ (D) Nadia Pinardi $^{1}$
}

Received: 18 December 2016 / Accepted: 26 September 2017 / Published online: 24 October 2017

(C) The Author(s) 2017. This article is an open access publication

\begin{abstract}
The use of a one-dimensional interdisciplinary numerical model of the coastal ocean as a tool contributing to the formulation of ecosystem-based management (EBM) is explored. The focus is on the definition of an experimental design based on ensemble simulations, integrating variability linked to scenarios (characterised by changes in the system forcing) and to the concurrent variation of selected, and poorly constrained, model parameters. The modelling system used was previously specifically designed for the use in "data-rich" areas, so that horizontal dynamics can be resolved by a diagnostic approach and external inputs can be parameterised by nudging schemes properly calibrated. Ensembles determined by changes in the simulated environmental (physical and biogeochemical) dynamics, under joint forcing and parameterisation variations, highlight the uncertainties associated to the application of specific scenarios that are relevant to EBM, providing an assessment of the reliability of the predicted changes. The work has been carried out by implementing the coupled modelling
\end{abstract}

This article is part of the Topical Collection on the 8th International Workshop on Modeling the Ocean (IWMO), Bologna, Italy, 7-10 June 2016

Responsible Editor: Gianmaria Sannino

Marco Zavatarelli

marco.zavatarelli@unibo.it

Giulia Mussap

g.mussap@sincem.unibo.it

Nadia Pinardi

nadia.pinardi@unibo.it

1 Dipartimento di Fisica e Astronomia, Alma Mater Studiorum Università di Bologna, Viale Berti Pichat 6/2, Bologna, Italy system BFM-POM1D in an area of Gulf of Trieste (northern Adriatic Sea), considered homogeneous from the point of view of hydrological properties, and forcing it by changing climatic (warming) and anthropogenic (reduction of the land-based nutrient input) pressure. Model parameters affected by considerable uncertainties (due to the lack of relevant observations) were varied jointly with the scenarios of change. The resulting large set of ensemble simulations provided a general estimation of the model uncertainties related to the joint variation of pressures and model parameters. The information of the model result variability aimed at conveying efficiently and comprehensibly the information on the uncertainties/reliability of the model results to non-technical EBM planners and stakeholders, in order to have the model-based information effectively contributing to EBM.

Keywords Marine biogeochemical modelling . Ecosystem-based management $\cdot$ BFM $\cdot$ Model uncertainties $\cdot$ Adriatic sea $\cdot$ Gulf of Trieste

\section{Introduction}

The global coastal ocean is an intensively studied part of the global ocean, because of its complex dynamics, its ecological and socio-economical importance and its sensitivity to changes (Mackenzie et al. 2004; Robinson and Brink 2006). This delicate system is often subject to strong, and continuously increasing, anthropogenic pressures. Moreover, climate variability and change interacts with the anthropogenic pressures, potentially amplifying ecosystem degradation (Artioli et al. 2008). Detecting and predicting the possible response of the system to anthropogenic and climate pressures is therefore a scientific challenge of major 
interest (Harley et al. 2006). Moreover, understanding and managing the ecological alterations occurring under anthropogenic pressure is a major challenge for managers and policy makers (Hoegh-Guldberg and Bruno 2010). The adoption of a marine ecosystem-based management (EBM) approach has therefore become essential. EBM (Slocombe 1993) involves the management and sustainable use of the marine resources (Atkins et al. 2011), considering natural changes and human activities as components of the larger ecosystem (Arkema et al. 2006; Coll and Libralato 2012).

Ecological models can effectively contribute to the implementation of EBM, providing insight and understanding on the functioning of the ecosystem to be managed, and contributing to predict consequences of potential impacts and pressures. The proper use of models as coastal management support tools, requires the validation of the results against available observations and analysis to investigate the consequences of parameter choices that are poorly constrained by observations and/or often referred to very general "average values" (Harley et al. 2006). In addition to that, communicating findings arising from the simulations to managers and policy makers require adequate procedures and protocols to define the prediction uncertainty. In fact, the uncertainty linked to the parametrization of processes is a major constraint for their use at management level (Fiechter 2012).

Developing a reliable and comprehensible communication system is therefore essential to provide information on complex topics with a degree of simpleness. The general idea is to deliver results with associated estimated uncertainty ranges, enabling stakeholders and managers to take the most appropriate decisions. One effective way to do this is by implementing a multi-parametrisation ensemble approach, involving a large number of numerical experiments, considering, in an integrated way, the sensitivity of the model results to parameters and forcing conditions, and defining scenarios of change that include the combined effect of climatic change and anthropogenic pressure (as detailed below).

Ensemble simulations are now routinely carried out in the weather and climate forecast fields, where a single forecast is replaced by an "ensemble" of forecasts, produced by varying the forecast initial conditions and/or the model parameters (Slingo and Palmer 2011), so that the forward in time-effective state of the (weather/climate) system should lie within the "spread" generated by the different time-dependent evolution of the ensemble members. The larger the "spread", the larger the uncertainty of the forecast/prediction should be. Such approach is adopted here and applied to the dynamics of the coastal ocean ecosystem, retaining the parameters variability approach, but analyzed jointly with variability in the forcing (scenario) conditions. In such a framework, the ensemble spread (variability between ensembles) provides a measure of the overall effect of the projected scenario conditions, while the spread within the individual ensembles provides an indication of the uncertainty of the scenario projection due to the model parameterisation. This way, if a model scenario simulation is particularly sensitive to a model parameter choice, the ensemble simulations for such scenario will show large spread of its members in the values of the response, thus giving indications of the (reduced) reliability of the projection.

In this work, this approach is explored by using a onedimensional physical-biogeochemical model (BFM-POM 1D) previously developed, implemented and tested in an area of the Gulf of Trieste with homogeneous hydrological properties (Mussap et al. 2016; Mussap and Zavatarelli 2017). The site choice is motivated by the extensive monitoring activities carried out in the gulf. The model implementation in this site is then proposed here as a "pilot effort" in the implementation of a relatively simple model tool. In fact, as stated in the previous papers, the modelling system is aimed to complement and integrate the scientific knowledge for coastal ocean sites interested by monitoring activities (data-rich areas). The objective is to provide a tool allowing to test the effectiveness of management options, accounting also for concurrent changes in the climatic characteristics. The previous efforts validated the model, defined the suitability of the system to replicate the changes in the biogeochemical functioning induced by the general variability of the physical environment and explored the role of the benthic-pelagic coupling in the general biogeochemical dynamics of the site.

Here, the crucial issue of the model reliability in projections determined by different policy actions is finally investigated. The ensemble approach applied to simulations of the marine food web dynamics is rather new (Fiechter 2012), and the general aim is to go beyond a purely model sensitivity study and to have a support tool for decision-making in presence of uncertainties (Ravetz 1986). Furthermore, our effort is a starting point for emulation research in the field of marine biogeochemistry. As Ratto et al. (2012) state: "Despite the stunning increase in computing power over recent decades, computational limitations remain a major barrier to the effective and systematic use of large-scale, process-based simulation models in rational environmental decision-making". Our effort proposes a reduced-order numerical model to be used for emulatorlike studies where sensitivity to model parameterisations is considered to be necessary to advance towards an usable environmental management tool.

A conceptual scheme of the work and methodology carried out is given in Fig. 1. Adopting a DPSIR (Drivers, Pressures. State, Impact, Response)-related (Rapport and Friend 1979; Oesterwind et al. 2016) terminology, the changing 
Fig. 1 Conceptual scheme representing of the structure of this study: the three scenarios, the impact variables analyzed for each of them and the statistical distributions developed as a function of the scenarios

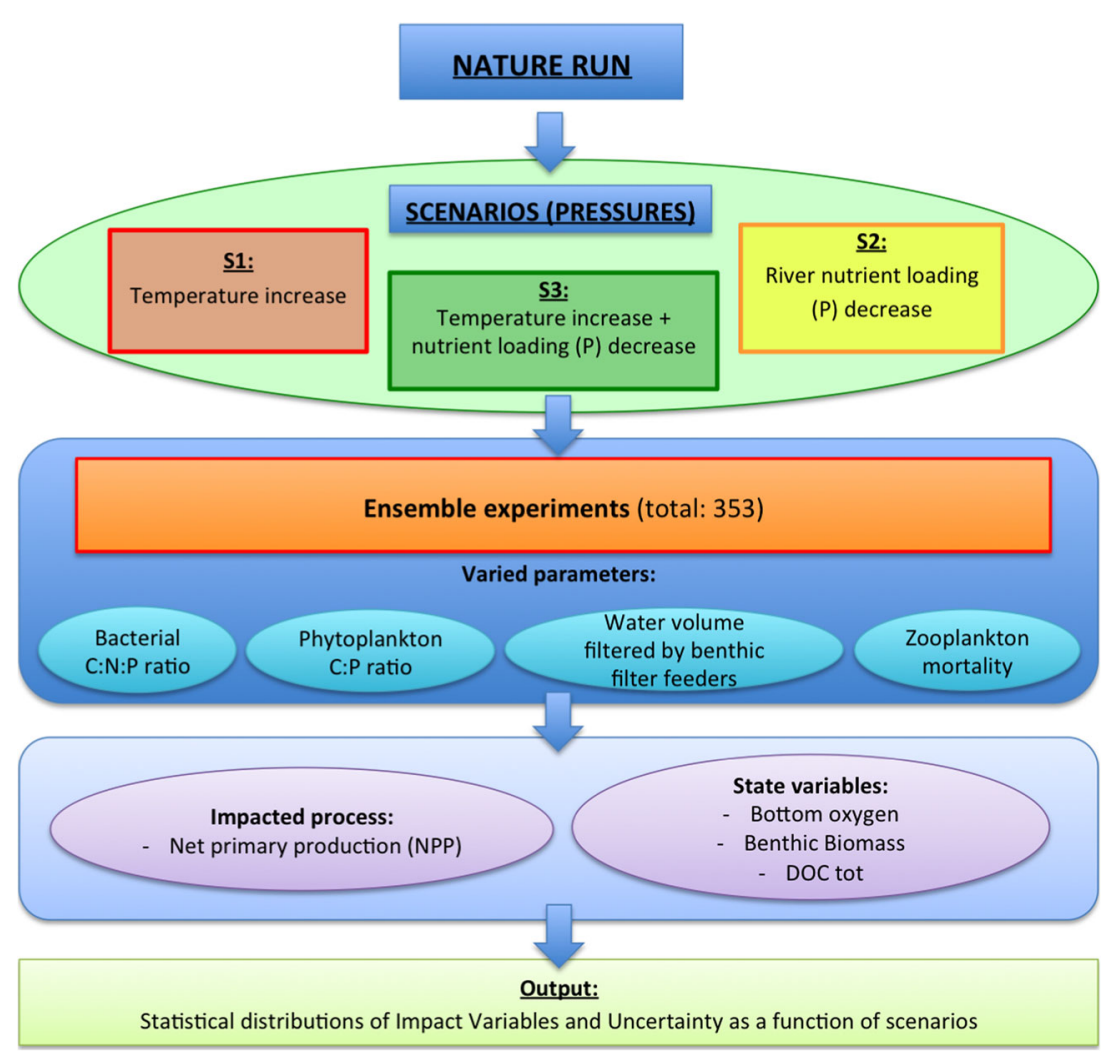

forcing applied in each scenario represents the "pressure", while some model state variables (bottom oxygen concentration, benthic biomass and integrated dissolved organic matter, hereafter defined as DOC) have been selected as representative of the system "state", while the integrated net primary productivity has been chosen to investigate the "impact" on the system.

Three pressure scenarios were taken into consideration corresponding to an increase in temperature (S1), a decrease in phosphate surface concentrations (S2) and a combination of the two (S3). The choice of the state variables listed above as representative of the system "state" was dictated by the following general consideration: bottom oxygen variability is indicative of the ventilation condition of the coastal environment, as it is well known that relatively high trophic conditions and strong vertical stratification might lead to anoxia phenomena in the coastal ocean (Rabalais et al. 2010, 2014). The dynamics of the benthic fauna (in particular, the filter feeder component: Gili and Coma 1998) has a strong influence on the dynamics of the pelagic environment, as it can significantly constrain the primary production process (Mussap and Zavatarelli 2017). Variation in the concentration level of dissolved organic matter can be indicative of the importance of the "microbial" food web (Kujawinski 2011) in the overall pelagic ecosystem functioning.

The chosen process experiencing an "impact" is the net primary productivity (hereafter NPP) expressed in milligrams of carbon per square meter per day, i.e. the balance between the photosynthesis process operated by the phytoplankton functional groups and their carbon losses due to rest and activity respiration. NPP can be considered as the main process fuelling the flow of matter and energy in the coastal marine ecosystem (Cloern et al. 2014). The choice was motivated by the kind of temperature and nutrient related scenarios adopted, that are directly acting on the NPP process (Falkowski et al. 1998).

Multi-parametrisation ensemble experiments were performed for each of these scenarios, by varying four BFM parameters: bacterial carbon $(\mathrm{C})$ to nitrogen $(\mathrm{N})$ to phosphorus $(\mathrm{P})$ ratio (hereafter $\mathrm{C}: \mathrm{N}: \mathrm{P}$ ), the phytoplankton carbon to phosphorus ratio (hereafter $\mathrm{C}: \mathrm{P}$ ), the daily specific rate of water volume filtered by benthic filter feeders $\left(V_{\mathrm{f}}\right.$ in cubic meters per milligram of carbon per day) and the zooplankton specific mortality $d_{\mathrm{z}}$ (per day). Details on the motivation and the rationale underlying the scenarios definitions, as well as the selection of the parameters to be systematically modified for the ensemble simulations, are given in Section 2.3, devoted to the description of the experimental design. The application of different scenarios to generate ensembles, jointly with the parameter variation is expected to entail important uncertainties linked to both the parametrisation of the major biogeochemical processes under projected changes of the system forcing functions. 


\section{Materials and methods}

\subsection{Study site: the Gulf of Trieste}

As for the previous studies (Mussap et al. 2016; Mussap and Zavatarelli 2017), the one-dimensional modelling exercise was carried out by implementing the model in the centre of the gulf at a site included in the area MA21 (Fig. 2), covered by six sampling stations of the Regional Environmental Protection Agency (ARPA-FVG), and considered homogeneous from a hydrological point of view (uniform spatio-temporal distribution and coherent variability of the hydrological properties). The ARPA-FVG monitoring activities have identified several "homogeneous" areas in the gulf (see http://www.arpaweb.fvg.it/daamc/gmapsdamc. asp). The MA21 area is representative of river-influenced waters, it covers an area $3-\mathrm{km}$ offshore from the coastline and it is called "offshore coastal" because it is under the direct influence of nutrient inputs from the Isonzo river but it does not directly include the river influenced coastal current system. Thus, our choice of the MA21 area to do scenario studies for different nutrient inputs. The proposed methodology can be easily replicated in other areas, as the one-dimensional structure of the model allows for the extensive ensemble simulations, an effort that would result in a prohibitive computational load if carried out with a three-dimensional model.

The main freshwater input is the Isonzo river, which regulates circulation and acts as a source of nutrients. The circulation is generally cyclonic, but intense and frequent

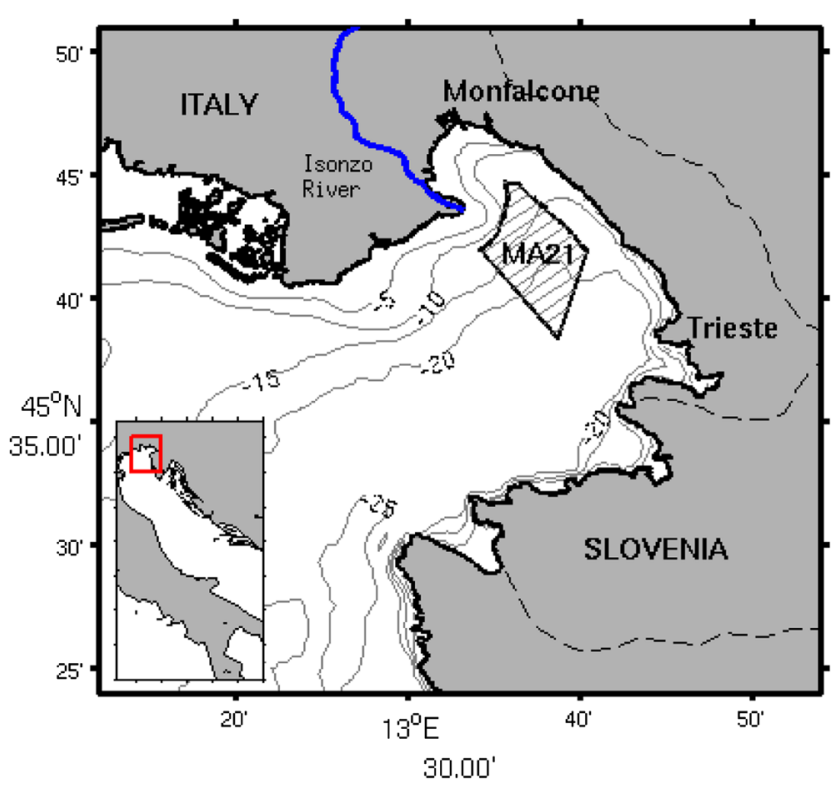

Fig. 2 Coastline and bathymetry of the Gulf of Trieste. The area labelled "MA21" is the region defined by ARPA-FVG as characterised by homogeneous hydrologic conditions wind events (from the northeastern quadrant) produce an east-to-west surface current (Malacic and Petelin 2009). River inputs and wind conditions are major factors in defining the trophodynamics of this area (Fonda Umani et al. 2007; Solidoro et al. 2007) influencing stratification and nutrient availability.

The gulf is subject to strong anthropogenic pressure and is characterised by high productivity (Fonda Umani 1996). In fact, the coast of the Gulf of Trieste is heavily populated and is a site of important harbours and activities related to tourism, fishing and aquaculture, making it one of the most polluted areas in the Adriatic Sea (Faganeli and Ogrinc 2009). Nutrient loads impact primary production and community composition, and consequently, biological activity strongly depends on the Isonzo river discharge, which may vary from year to year. This anthropogenic influence contributes to the interannual variability of chemical parameters (Mozetic et al. 1998).

Generally speaking, the gulf, as most of the Mediterranean, is P-limited. Changes in ecology and chemistry have been observed as a consequence of the stress the gulf is constantly under, which leads to excess nutrient loads and therefore eutrophication. In fact, bottom waters have been observed to be episodically depleted in oxygen, experiencing anoxic conditions (Faganeli et al. 1991).

\subsection{Model description}

The coupled numerical model implemented here (BFMPOM 1D) is composed by the open-source Biogeochemical Flux Model (BFM, http://bfm-community.eu/) and the onedimensional version of the Princeton Ocean Model (POM) (Blumberg and Mellor 1987), coupled "on-line". The equations describing the coupling between the two models can be found in Mussap et al. (2016).

The BFM pelagic component is described in (Vichi et al. 2007), while the benthic component, based on Ebenhöh et al. (1995) and Ruardij and Raaphorst (1995), has been implemented in the BFM-POM 1D by Mussap and Zavatarelli (2017).

The bottom depth was set at $16 \mathrm{~m}$ (average depth of the Gulf of Trieste), and the vertical resolution is defined by 30 levels, with a logarithmic distribution near the surface and bottom boundaries. As detailed in Mussap et al. (2016), the implementation of the hydrodynamic model was chosen to be diagnostic for the temperature and salinity profiles (prescribed monthly climatological temperature and salinity vertical profiles). This is made possible by the extensive observational activities carried out by the Regional Environmental Protection Agency that allows for the reconstruction of a reliable climatology of the hydrological properties. The prescribed monthly varying temperature and salinity 
profiles eliminate the problem of model drift and reduce the problem of an incorrect representation of the spatiotemporal variability linked to the model lack of horizontal resolution. Moreover, the biogeochemical state variables have been validated against independent data (Mussap et al. 2016; Mussap and Zavatarelli 2017) and results indicate that the model, despite its simple structure, has skill in reproducing the observed seasonal variability of marine trophic structure at MA21.

Under this implementation characteristics, the only surface physical forcing function applied is the monthly varying climatological wind stress, which was obtained from the 6-h ECMWF ERA interim reanalysis (Berrisford et al. 2009) relative to the period 2000-2013, in order to be coherent with the observational period of the hydrological data (see below).

The biogeochemical system component is forced by monthly values of surface solar radiation composed also in this case from ERA-interim, surface nutrients and seasonally varying inorganic suspended matter vertical profiles (ISM). Surface incident shortwave radiation (photosynthetically available radiation, PAR) is forcing the primary production process. PAR penetrating the water column is attenuated on the basis of phytoplankton (self-shading) and detritus concentration (both prognostically computed), and prescribed observed ISM profiles.

The surface nutrient boundary condition is a surface nudging term (Haney 1971; Vichi et al. 1998a, b, 2003a, b, 2004; Carniel et al. 2007) constraining the surface nutrient concentrations (phosphate, nitrate, ammonium and silicate) to monthly varying observed values:

$\left.K_{\mathrm{V}} \frac{\partial N}{\partial t}\right|_{z=0}=-\gamma\left(N-N^{*}\right)$

where $N$ is a generic dissolved nutrient state variable, $K_{\mathrm{V}}$ is the turbulent vertical diffusion coefficient $\left(\mathrm{m}^{2} / \mathrm{s}\right), N^{*}$ is the observed value and $\gamma$ is an empirical relaxation velocity chosen to be $0.6 \mathrm{~m} /$ day. The chosen nudging surface boundary condition accounts for the external nutrient inputs from rivers.

The initial conditions for biogeochemical pelagic components are vertically homogeneous (see Mussap et al. 2016). The temperature, salinity, surface nutrient concentrations and monthly climatologies were compiled from observations collected in the gulf in the period 2000-2013. Information regarding the climatologies and sources of the forcing functions can be found in Mussap et al. (2016).

It has to be stressed that the model forcing functions, as well as the prescribed ISM vertical profiles are climatological (long-term averages) values; therefore, the obtained results should be considered as indicative of an average system behaviour.
The BFM structure is based on chemical functional families (CFFs) and living functional groups (LFGs) (Vichi et al. 2007) (Fig. 3).

The LFGs are producers (e.g. phytoplankton), consumers (e.g. zooplankton) and decomposers (bacteria). The dynamics of each LFG are defined by population (growth, migration, mortality) and physiological (photosynthesis, ingestion, respiration, excretion, egestion) processes. The model resolves four phytoplanktons (LFGs), four zooplanktons (LFGs), one pelagic bacteria (LFG), five benthic organisms (LFGs) and two benthic bacteria (LFGs).

The pelagic CFFs are phosphate, nitrate, ammonium, silicate and reduction equivalents The benthic CFFs are phosphate and ammonium in the oxic and anoxic layers, nitrate, silicate and reduction equivalents. Dissolved oxygen and $\mathrm{CO}_{2}$ are also taken into account in both the pelagic and benthic domain. Organic matter is divided into particulate (POM) and dissolved (DOM), and its dynamics are regulated by biological activity (uptake and release).

The BFM pelagic and benthic domains are directly coupled through sedimentary and diffusive fluxes at the watersediment interface. The benthic model resolves the oxic and anoxic layers; within the total sediment thickness, the carbon, nitrogen, phosphorus and silicon detrital components have different penetration depths. and the model describes the benthic fauna dynamics (determining bioturbation and bioirrigation) and the microbially mediated organic matter mineralization. Benthic primary production and sediment resuspension processes are not considered in the current formulation.

\subsection{Experimental design}

All the ensemble simulations were performed by forcing the modelling system in perpetual year mode (monthly varying surface forcing functions and prescribed temperature, salinity and suspended sediment vertical profiles). Using a climatological perpetual forcing for the control simulations allowed us to validate the modelled marine food web (Mussap et al. 2016). Thus, generating food web changes by altering the characteristics of a current realistic climatological state of the system, appears to be a consistent experimental design aimed to evaluate uncertainties (Milliken 1987). Moreover, by constraining the model to the observed (or coherently altered) climatologies, the uncertainties estimation arising from the ensemble runs should be mostly depending on the purely biogeochemical dynamics, i.e. the most important (and critical) from an environmental management point of view. On the other hand, the importance and the extent of this uncertainties estimation effort should be considered in a climatological (long-term averaged system state) perspective. 
Fig. 3 Scheme of the pelagic and benthic state variables and interactions of the BFM. Living (organic) chemical functional families (CFFs) are indicated with bold-lined square boxes, non-living organic CFFs with thin-lined square boxes and inorganic CFFs with rounded boxes. The fat double-headed arrows indicate fluxes of the benthic-pelagic coupling
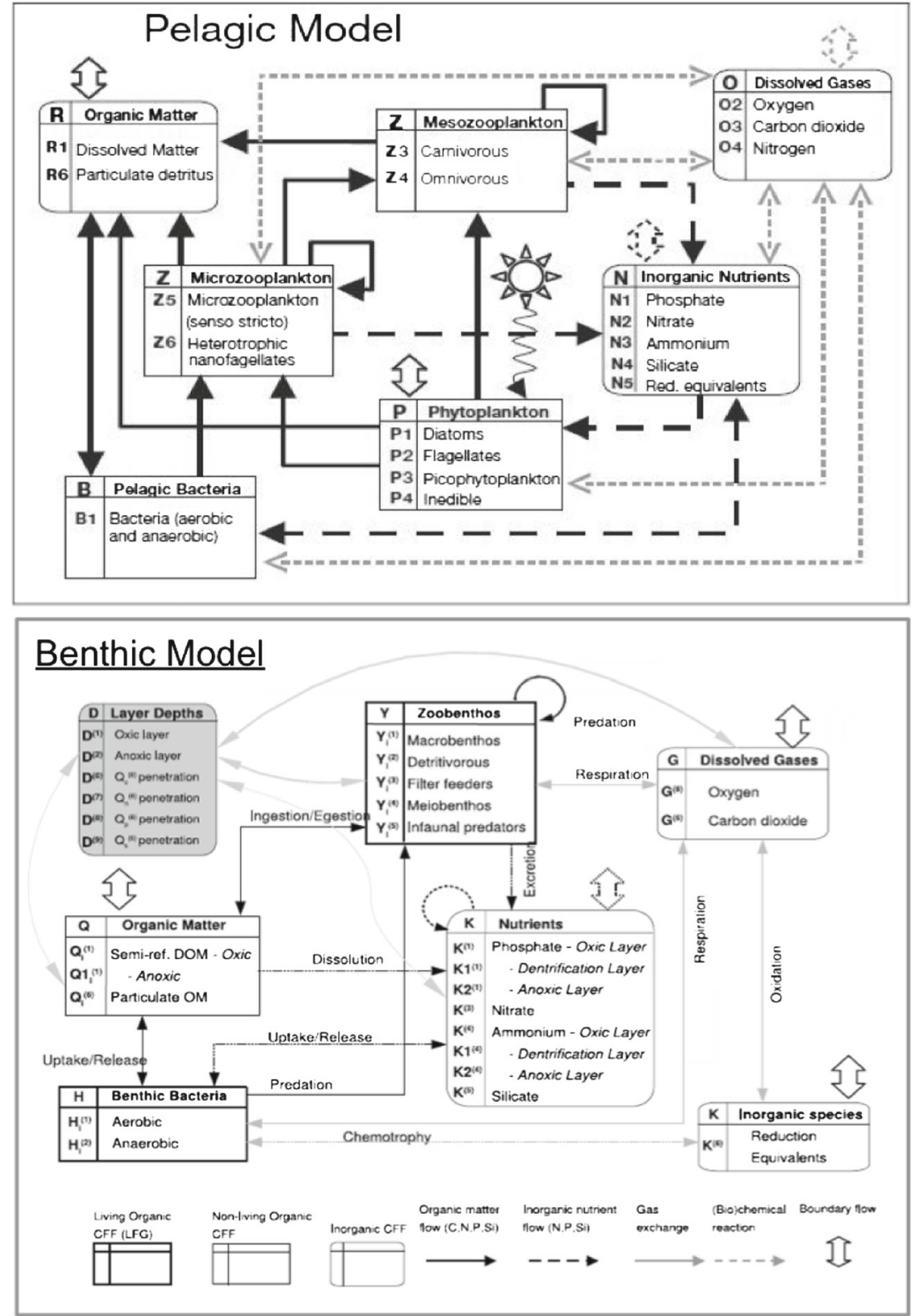

The scenarios were chosen as representative of two important "pressures" acting on the coastal ocean: the climate and the land-based input-mediated pressure. Both pressures can be considered as "anthropogenic", but their action on the coastal ocean can be considered as respectively "indirect" and "direct" (Oesterwind et al. 2016).

The climate pressure is represented by the warming of the surface ocean waters as a consequence of the global warming induced by the anthropogenic increase of atmospheric greenhouse gases (Schneider 1990; IPCC 2014). It can be considered as a pressure acting indirectly on the coastal ocean, since it is mediated by the complex and nonlinear dynamics of the climate system. The latest projections about the increase of the surface temperature (IPCC 2014) states that "Surface temperature is projected to likely exceed $1.5{ }^{\circ} \mathrm{C}$ " (IPCC 2014). Therefore, the temperature-related scenarios applied (S1, see Fig. 1) were generated by progressively increasing the sea surface temperature (SST) monthly values by $+0.5{ }^{\circ} \mathrm{C}$ from the climatological value up to $+1.5^{\circ} \mathrm{C}$, and by applying a corresponding subsurface warming linearly decreasing with depth, so that the temperature at the bottommost sigma layer remains identical to the climatological value. The S1 temperature-related scenario group (Fig. 1) is then constituted by a set of four scenarios, each of them has a characteristic of a SST increase, $\Delta T_{\mathrm{SST}}=0.0,0.5,1.0,1.5^{\circ} \mathrm{C}$. 


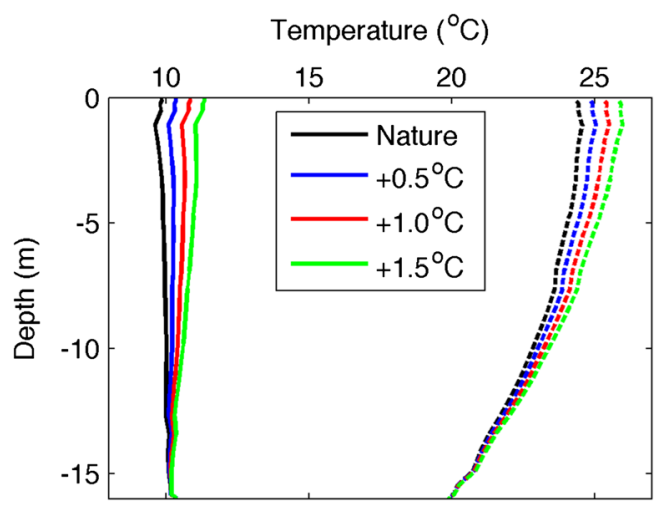

Fig. 4 January (continuous line) and August (dashed line) temperature vertical profiles of present day conditions and of the S1 scenario (increase in surface temperature)

Figure 4 reports as an example the climatological (defined as "Nature" condition) and the modified scenarios temperature profiles for the months of February and August. The scenario choice of applying a depth (inversely)dependent warming, was motivated by the willingness to enquire into one aspect of the possible warming-related system modification: the increase of the vertical stratification, that is thought to influence quantitatively and qualitatively the marine primary production (Scavia et al. 2002; Behrenfeld et al. 2006) and the coastal marine ecosystem dynamics (Coma et al. 2009).

It has to be stressed that climatic change will not affect the coastal ocean only in terms of purely temperaturerelated changes, but the wind forcing will also be affected. In this study, we did not consider climatic scenarios based on changes in the wind forcing because of a missing consensus view about a scenario of change such as the one proposed by IPCC (2014). The pressure determined by the nutrient land-based input can be considered as directly acting on the coastal ocean environmental dynamics. The exclusive focus on the reduction of the land-based nutrient load conveyed to the coastal ocean, is motivated by the successful application of the EU regulations (648/2004 and 259/2012) concerning the abatement of phosphate (the limiting nutrient in the Mediterranean, including the northern Adriatic Sea: Marty et al. 2002, Krom et al. 2004, Solidoro et al. 2009) and phosphorus compounds in detergents. The implementation of such abatement policy contributed to a marked reduction of the phosphate riverload affecting the Mediterranean Sea (Ludwig et al. 2009, 2010) and resulting, for the northern Adriatic Sea, in a rearrangement of its trophic state towards more oligotrophic conditions (Solidoro et al. 2009; Djakovac et al. 2012). The S2 scenario group (Fig. 1) is then constituted by a set of ten scenarios obtained by progressively decreasing the monthly climatological surface phosphate concentrations (used to formulate the surface boundary conditions) in 10\% steps, from the climatological values to a value being just $10 \%$ of it. The interacting effect of these two pressures has been then evaluated in the S3 scenario (Fig. 1), by simultaneously applying them to the system. These scenarios were run singularly as well as jointly, resulting in a set of 40 scenario experiments (4 temperature and 10 phosphare surface concentrations), including the simulation carried out under current climatological forcing (nature run).

It has to be stressed that, although the scenario definitions are acknowledging warming and P-reduction trends for which consensus and/or observational evidence exists, the chosen scenarios have to be understood mainly as methodological examples of the proposed ensemble approach. Subsequently, 15 scenario runs were sub-sampled in order to develop ensembles considering variation in the forcing condition and in the model parameters. The sub-sampling affected the number of surface phosphate concentration scenarios, that was reduced from ten to four (climatological value and 25,50 and $75 \%$ reduction) in order to have a manageable number of ensemble simulations runs to be carried out.

The parameters to be varied in the ensemble simulations (bacterial C:N:P, phytoplankton $\mathrm{C}: \mathrm{P}, V_{\mathrm{f}}, d_{\mathrm{z}}$ ) were selected because their value is either very often referred to average conditions (bacterial $\mathrm{C}: \mathrm{N}: \mathrm{P}$, phytoplankton $\mathrm{C}: \mathrm{P}$ ) or is poorly constrained by specific in situ or laboratory-based observations $\left(V_{\mathrm{f}}, d_{\mathrm{z}}\right)$, and because of their importance in modulating the biogeochemical processes of the marine ecosystem. They act then as a source of uncertainty due to lack of knowledge and/or to their inherent natural variability. Obviously, this selected suite of parameters is not exhaustive of the problem of poorly known parameter values, but are, however, crucial to define important biogeochemical processes such as net primary production, nutrient bacterial re-mineralization/utilisation, secondary production and benthic/pelagic predation.

The baseline value for the adopted bacterial molar C:N:P ratio is the Goldman et al. (1987) ratio (45:9:1). The BFM representation of the bacterial dynamics (Baretta-Bekker et al. 1997; Polimene et al. 2006) allows bacteria to act as inorganic nutrient remineralisers or as utilisers (and therefore as phytoplankton competitors for nutrients) on the basis of their C:N:P ratios: higher/lower C:P and/or C:N bacterial ratios (compared to Goldman et al. 1987) determine the bacterial utilisation/remineralisation of inorganic nutrients. The different biogeochemical functionality of the bacteria is associated to the establishment of the herbivorous or microbial trophic web and on trophic conditions shifting from eutrophic to oligotrophic (Legendre and Rassoulzadegan 1995; Fagerbakke et al. 1996; Vrede 1998; Vichi et al. 
2003a). Given the "average" meaning of the Goldman et al. (1987) ratio, the establishment of a threshold value for the definition of the functional role of the bacteria in a numerical model is therefore subject to uncertainties, depending on the characteristics of the bulk bacterial population and on the trophic state of the system under analysis.

The selection of the phytoplankton C:P ratio as a parameter to be varied for the ensemble simulation is essentially due to the same reasons. The average ratio is the Redfield (1934) ratio (106:1). In BFM, this ratio is used to define the Droop (1973, 1975) and Nyholm (1977) nutrient dynamics in phytoplankton, implemented according to Baretta-Bekker et al. (1997). The implementation allows a partial decoupling of the carbon and the nutrient dynamics, allowing the internal phytoplankton C:P ratio to vary up to to $50 \%$ of the Redfield (1934) value, therefore allowing phosphorus luxury storage/consumption. The same considerations would apply to the phytoplankton $\mathrm{C}: \mathrm{N}$ ratio, but given the overall P-limited nature of the implementation site, the variation of the parameterised reference ratio was applied only to the $\mathrm{C}: \mathrm{P}$ ratio of all the four phytoplankton functional groups considered by BFM.

The filter feeder activity constitutes an important element of the benthic-pelagic coupling, capturing suspended particles and directly regulating primary production (Winter 1978; Officer et al. 1982; Gili and Coma 1998). A previous modelling effort (Mussap and Zavatarelli 2017) demonstrated the importance of such processes in constraining the trophic characteristics of the implementation site and the adopted (validated reference run) baseline value for the $V_{\mathrm{f}}$ parameter was $210^{-3} \mathrm{~m}^{3}\left(\mathrm{mg} \mathrm{C}\right.$ day $\left.^{-1}\right)$, a value which is in line with the estimates of Winter (1978), Mohlenberg and Riisgard (1979), Officer et al. (1982) and Ricciardi and Bourget (1998). However, the estimates point to a significant variability (and therefore uncertainty) in dependence of the different macroinvertebrates that in BFM are represented by the single "filter feeders" functional group.

The background (non-predation)-specific mesozooplankton mortality $\left(d_{\mathrm{z}}\right)$, that accounts for $25-35 \%$ of the total zooplankton mortality (Hirst and Kiorboe 2002), is the fourth and last parameters whose variations compose the set of the ensemble simulations. The baseline value for the two mesozooplankton functional groups resolved by BFM (carnivorous and onnivorous mesozooplankton) is 0.02 and $0.01 \mathrm{day}^{-1}$, respectively (Dubovskaja et al. 2014). Including the variation of such parameter into the general ensemble simulation generation implies a modification of the top down control exerted by the ecosystem on the "impacted" primary productivity and therefore an estimation of the uncertainties associated to such parameterised process.

All four parameters listed above were varied in the $\pm 20 \%$ range with respect to be baseline value, as schematised in Table 1 . When only single parameters were varied, the variation step was of $1 \%$ (i.e. $-20,-19,-18, \ldots,+20 \%$ ), while when two parameters were simultaneously modified, the step was of $5 \%$ (i.e. $-20,-15,-10, \ldots,+20 \%$ ). Each ensemble (Fig. 1) was then constituted by 352 runs. Here, the ensemble results are represented by means of frequency distribution histograms for integrated NPP, bottom oxygen, total benthic biomass and integrated DOC.

The scenario characteristics selected for the ensemble development are schematised in Table 2. Overall, 16 ensembles were generated for a total of 5632 ensemble members, each of which was numerically stable. Note that ensemble A1 indicates the ensemble development from the "nature" run and is hereafter defined as the "control" ensemble.

Each simulation composing each ensemble had a 5-year integration time length, as previous work with the same implementation of the BFM-POM1D system (Mussap et al.
Table 1 Table of multi-parametrised ensemble experiments involving bacterial $\mathrm{C}: \mathrm{N}: \mathrm{P}$ ratio, phytoplankton $\mathrm{C}: \mathrm{P}$ ratio, the volume filtered by the filter feeders and zooplankton mortality

\begin{tabular}{|c|c|c|c|c|}
\hline & $\begin{array}{c}\text { Bacterial } \\
C: N: P \text { ratio }\end{array}$ & $\begin{array}{c}\text { Phytoplankton } \\
\text { C:P ratio }\end{array}$ & $\begin{array}{c}\text { Zooplankton } \\
\text { mortality }\end{array}$ & $\begin{array}{l}\text { Volume filtered } \\
\text { by filter feeders }\end{array}$ \\
\hline $\begin{array}{c}\text { Bacterial } \\
C: N: P \text { ratio }\end{array}$ & $\begin{array}{c} \pm 20 \% \\
-20: 1: 20 \\
\text { Experiments: } 40\end{array}$ & & - & \\
\hline $\begin{array}{c}\text { Phytoplankton } \\
\text { C:P ratio }\end{array}$ & $\begin{array}{c} \pm 20 \% \\
-20: 5: 20 \\
\text { Experiments: } 64\end{array}$ & $\begin{array}{c} \pm 20 \% \\
-20: 1: 20 \\
\text { Experiments: } 40\end{array}$ & - & - \\
\hline $\begin{array}{c}\text { Zooplankton } \\
\text { mortality }\end{array}$ & $\begin{array}{c} \pm 20 \% \\
-20: 5: 20 \\
\text { Experiments: } 64\end{array}$ & - & $\begin{array}{c} \pm 20 \% \\
-20: 1: 20 \\
\text { Experiments: } 40\end{array}$ & \\
\hline $\begin{array}{l}\text { Volume filtered } \\
\text { by filter feeders }\end{array}$ & - & - & $\begin{array}{c} \pm 20 \% \\
-20: 5: 20 \\
\text { Experiments: } 64\end{array}$ & $\begin{array}{c} \pm 20 \% \\
-20: 1: 20 \\
\text { Experiments: } 40\end{array}$ \\
\hline & Total & nber of experim & ts: 352 & \\
\hline
\end{tabular}

Variations involved $\pm 20 \%$ of the nature run values. The steps were of $1 \%$ for variations of single variables, and of 5\% when different variables were crossed. In total, each ensemble was composed by 352 members. Shaded cells are duplicate crossings 
Table 2 Table of the scenario multi-parametrised ensemble experiments and their reference number. Ensemble number 1 is the control ensemble

\begin{tabular}{lllll}
\hline Temperature & \multicolumn{4}{l}{ Multiples of phosphate } \\
\cline { 2 - 5 } increase $\left({ }^{\circ} \mathrm{C}\right)$ & 1.0 & 0.75 & 0.5 & 0.25 \\
\hline+0.0 & $\mathrm{~A} 1$ & $\mathrm{~A} 2$ & $\mathrm{~A} 3$ & $\mathrm{~A} 4$ \\
+0.5 & $\mathrm{~B} 1$ & $\mathrm{~B} 2$ & $\mathrm{~B} 3$ & $\mathrm{~B} 4$ \\
+1.0 & $\mathrm{C} 1$ & $\mathrm{C} 2$ & $\mathrm{C} 3$ & $\mathrm{C} 4$ \\
+1.5 & $\mathrm{D} 1$ & $\mathrm{D} 2$ & $\mathrm{D} 3$ & $\mathrm{D} 4$ \\
\hline
\end{tabular}

2016; Mussap and Zavatarelli 2017) indicated that such integration time was ensuring the achievement of a stable seasonal cycle. The results shown were extracted from the last year of integration.

\section{Simulation experiments}

\subsection{Control ensemble experiments}

The control ensemble carried out with "present day" forcing (A1, Fig. 5) was developed by varying the parameters listed in Section 2.3 and according to Table 1. Results are shown relatively to the selected "state" variables and "impacted" process listed in Section 2.3 by means of histograms, in order to highlight their distribution and variability with respect to the "nature" run (Fig. 5). The continuous red line indicates the nature run value.

A $t$ test performed on the ensembles revealed a normal distribution at 5\% significance level for all four histograms shown in Fig. 5. The means, standard deviation and ranges for each distribution listed in Table 3 and compared with the A1 ensemble means are virtually indistinguishable from the nature run values, confirming an appropriate parameterisation of the former. In fact, both the ensemble mean and the nature run fall within the highest frequency bin. Standard deviations and ranges are, relative to the average values, very similar to each other, with the exception of the bottom oxygen which shows smaller standard deviation and range.

\subsection{Scenario simulations}

In order to understand how the uncertainty due to the parameter choices for A1 reflects on the scenario studies, 39 simulations were carried out under scenario conditions S1, $\mathrm{S} 2$ and S3 with the nature run parametrisation. Results of the 39 scenario experiments (plus the nature run) are described by the contour plots of Fig. 6, which show the annually averaged value obtained from each scenario.

The characteristic that immediately emerges from Fig. 6 is how little temperature ( $y$-axis) and how much phosphate concentration ( $x$-axis) determine changes in the system. In fact, temperature does not seem to play a major changing role influencing NPP, benthic biomass and integrated DOC (Fig. 6, panels a, c, and d, respectively). This is not true for
Fig. 5 Histograms of the control ensemble, computed from the 352 members of the multi-parameter ensemble. The red continuous line represents the nature run value. Panels correspond to integrated NPP, bottom oxygen, benthic biomass and total DOC
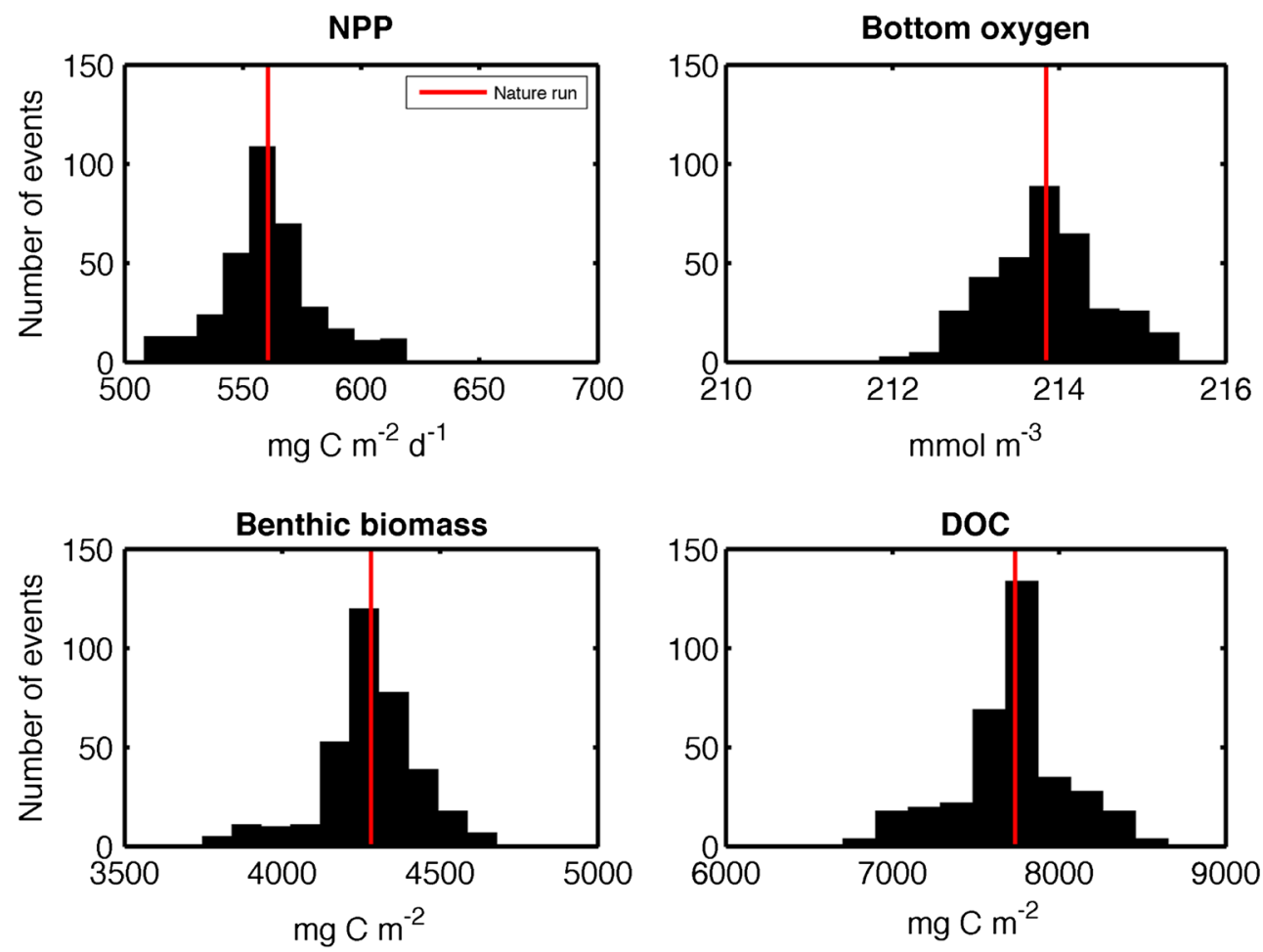
Table 3 Nature run: annually averaged values. Control ensemble (A1): mean, standard deviation and range of variation computed. The numbers in parenthesis refer to the standard deviation percentage computed with respect to the mean value

\begin{tabular}{llllll}
\hline & Nature run & \multicolumn{2}{l}{ Control ensemble (A1) } \\
\cline { 3 - 6 } Variable & Average & Average & Std. dev. & Range & Units \\
\hline Integrated NPP & 560.7 & 560.7 & $21.5(3.8 \%)$ & $110.9(19.8 \%)$ & $\mathrm{mg} \mathrm{C} \mathrm{m}^{-2}$ day $^{-1}$ \\
Bottom O & 213.8 & 213.8 & $0.7(0.3 \%)$ & $3.6(1.7 \%)$ & $\mathrm{mmol} \mathrm{m}^{-3}$ \\
Benthic biomass & 4281.2 & 4281.6 & $155.3(3.6 \%)$ & $933.9(21.8 \%)$ & $\mathrm{mg} \mathrm{C} \mathrm{m}^{-2}$ \\
Integrated DOC & 7735.5 & 7735.9 & $341.5(4.4 \%)$ & $1953.4(25.3 \%)$ & $\mathrm{mg} \mathrm{C} \mathrm{m}^{-2}$ \\
\hline
\end{tabular}

bottom oxygen concentrations (Fig. 6b), that decrease with increasing temperature. This decrease could be explained by the fact that oxygen solubility is inversely proportional to temperature (Henry's law). However, this can also be attributed to the conditions of increased stratification, which limits the ventilation of the lower water column, rather than to the increased organic matter to be respired.

While bottom oxygen reaches its maximum values when no change in temperature is applied and phosphate is strongly decreased, all other variables have the highest average values when phosphate concentrations are maintained at today's concentrations. In fact, they do not seem to be strongly influenced by a temperature increase, except for the integrated DOC, which slightly increases with increasing temperature. Overall, Fig. 6 suggests that a reduction in phosphate concentration may cause a stronger system alteration than an increase in temperature (and therefore stratification).

The 40 scenario experiments (depicted in Fig. 6) were sub-sampled by choosing to select 15 temperature and surface nutrients forcing conditions to be run with the 352 parameter combinations of the ensemble exercise. The ensemble scenario characteristics and the corresponding ensemble run name are reported in Table 2.

The variation of the ensemble averages corresponding to the scenarios adopted (and depicted in Fig. 7), provides an indication of the overall sensitivity of the modelled system to the changing forcing conditions. It can be easily noted that the variation of the ensemble averages with respect to the changing forcing conditions is essentially identical to the average values obtained when only forcing conditions were changed (see Table 3 and Fig. 6).
Fig. 6 Contour plots of the 39 (+ nature run) scenario experiments (represented with black dots). Multiples of phosphate on the $x$-axis and additional degrees on the $y$-axis. Panels correspond to integrated NPP, bottom oxygen, benthic biomass and integrated DOC
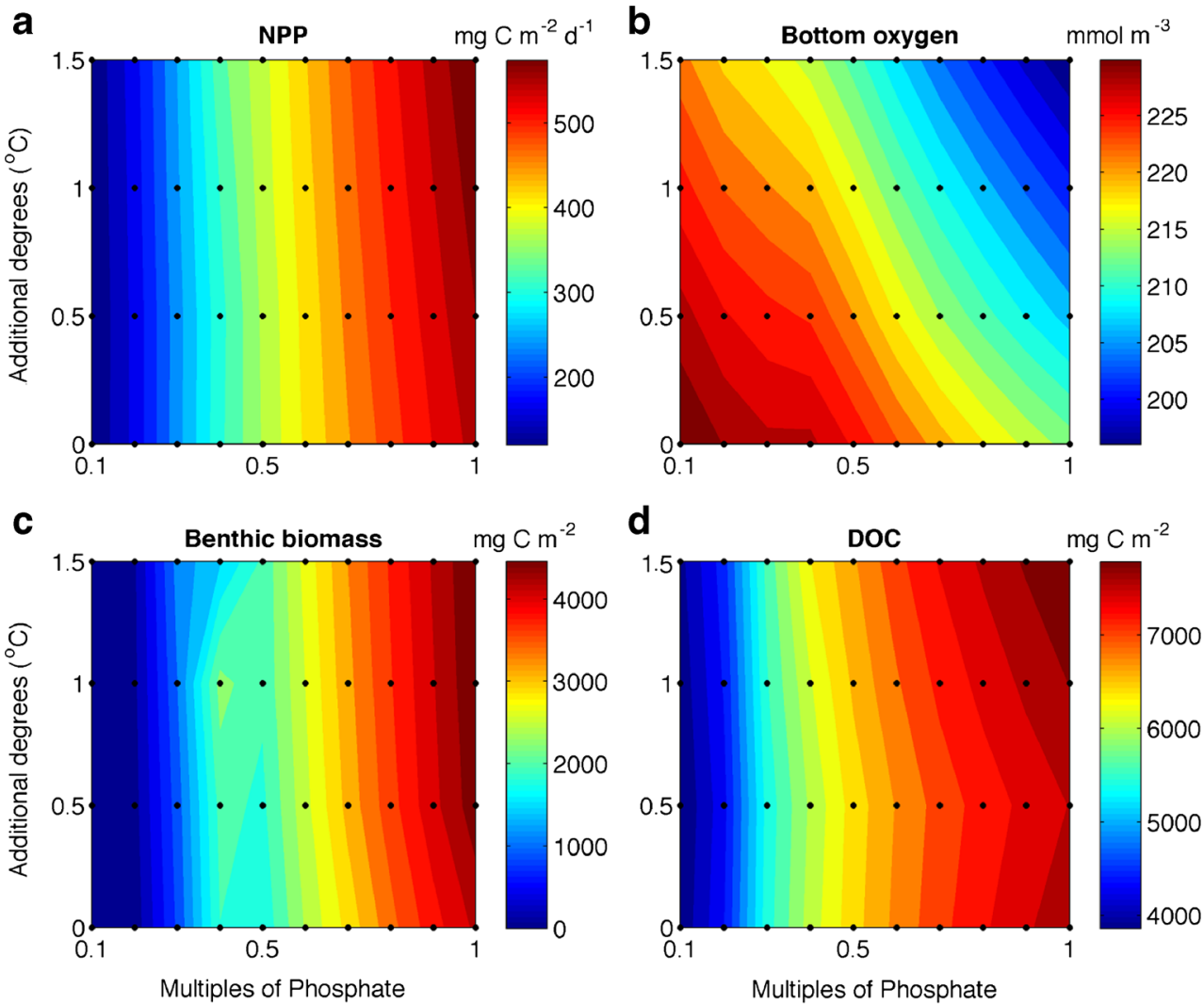
Therefore, an analysis of the ensemble runs results based solely on the shift of the ensemble average value provides little insight about the uncertainties associated to the joint variability of the forcing and the parameter choices. More important are the changing characteristics of the ensemble distributions determined by the joint variation of the forcing and the parameter values. For instance, Fig. 8 shows the frequency distribution of the values relative to the same properties shown in Fig. 7, arising from the $\mathrm{S} 1$ (temperature variation) scenarios (A1, B1, C1 and D1 of Table 2). Similarly, Fig. 9 shows the histograms corresponding to the S2 (surface phosphate flux) scenarios (A1, A2, A3, and A4 of Table 2). Both figures provide a further confirmation of the finding previously described: phosphate input is a major driver of change, with temperature playing a relevant role only with respect to the bottom oxygen concentration. The frequency distribution of the ensembles was checked for normality ( $t$ test) and was confirmed at the 5\% significance level with the only - albeit notable-exceptionbeing the frequency distribution of the benthic biomass (discussed later) for A3 (Fig. 9c). However, the roughly normal shape of each ensemble distribution associated to specific scenarios distribution changes considerably, indicating that the uncertainty affecting the simulated state variables and processes, is related to the joint role of variability in the pressures and to the parameter choices.

\subsection{Assessing uncertainties}

We investigate this issue by showing in Fig. 10 the coefficient of variation (standard deviation normalised by the value of the respective ensemble mean). Such coefficient is indicative of the "spread" affecting the results of each ensemble: the larger the spread, the less robust are the results pertinent to each scenario, being affected by the choice of the parameter set.

A preliminary inspection of Fig. 10 already indicates that the ensemble variability of the state variables and processes investigated show different values. It is very low for the bottom oxygen (Fig. 10b) concentration (order of $10^{-3} \%$ ), it has relatively low values for the NPP (Fig. 10a) and the DOC (Fig. 10d) concentration (ranging between 2 and 6\% and between 4.5 and $5.5 \%$ respectively), while significant variability is shown by the total benthic biomass values (ranging between 4 and 20\%). This finding indicates that the effect of the joint variation of the forcing functions and model parameters produces different degrees of uncertainty on the components of the modelled system. The impact on the analyzed state variables and process is, however, not only merely quantitative. Figure 10 suggests that, for the set of scenario adopted to carry out the ensemble experiments, the pattern of uncertainty variation is peculiar. The (relatively low) NPP (Fig. 10a) uncertainty shows a pattern
Fig. 7 Contour plots of the ensemble average value obtained from the 15 Ensemble runs. $X$ and $Y$ axis values and properties plotted as in Fig. 6
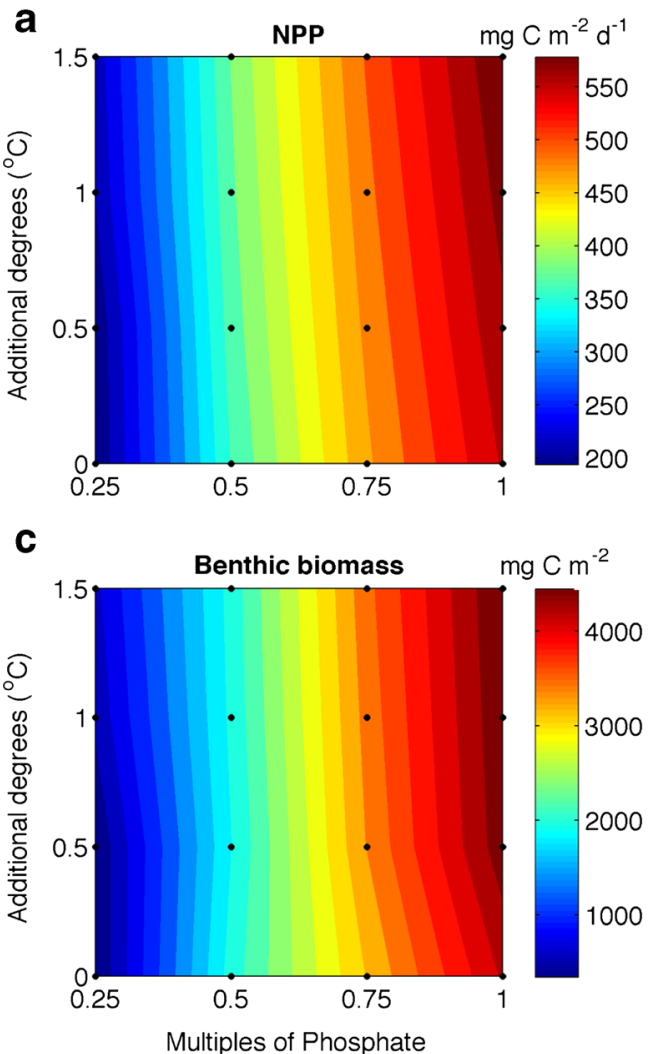

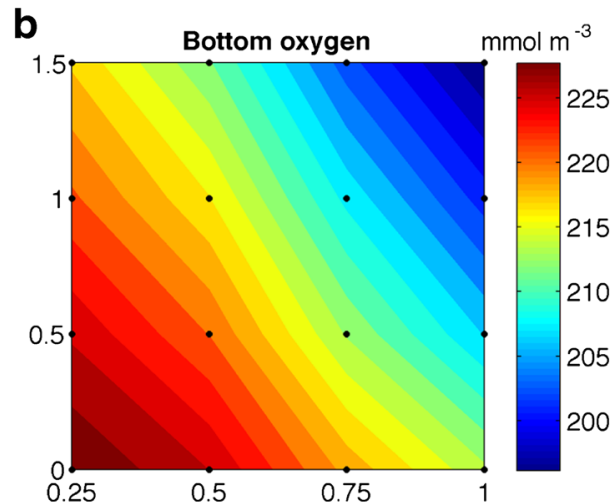

d

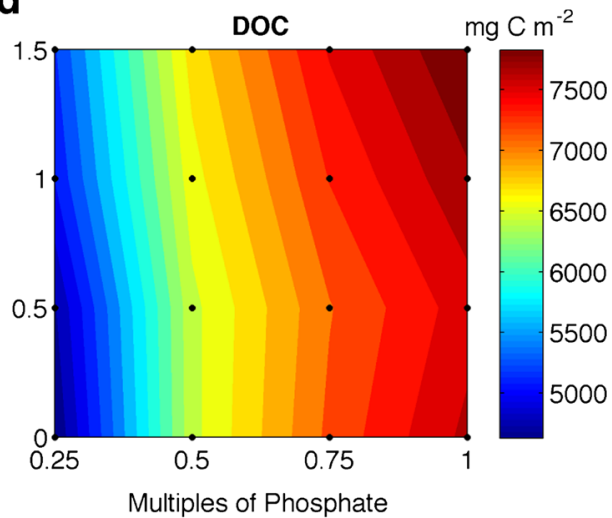


Fig. 8 Histograms of the 352 members ensemble runs carried out for S1 scenarios (+ control ensemble in black). Variables represented are integrated NPP (a), bottom oxygen (b), benthic biomass (c) and integrated DOC (d). Refer to Table 2 for information on the scenario associated to the ensemble number

Fig. 9 Histograms of the 352 members ensemble runs carried out for the $\mathrm{S} 2$ scenarios (+ control ensemble in black). Variables represented are integrated NPP (a), bottom oxygen (b), benthic biomass (c) and integrated DOC (d). Refer to Table 2 for information on the scenario associated to the ensemble number
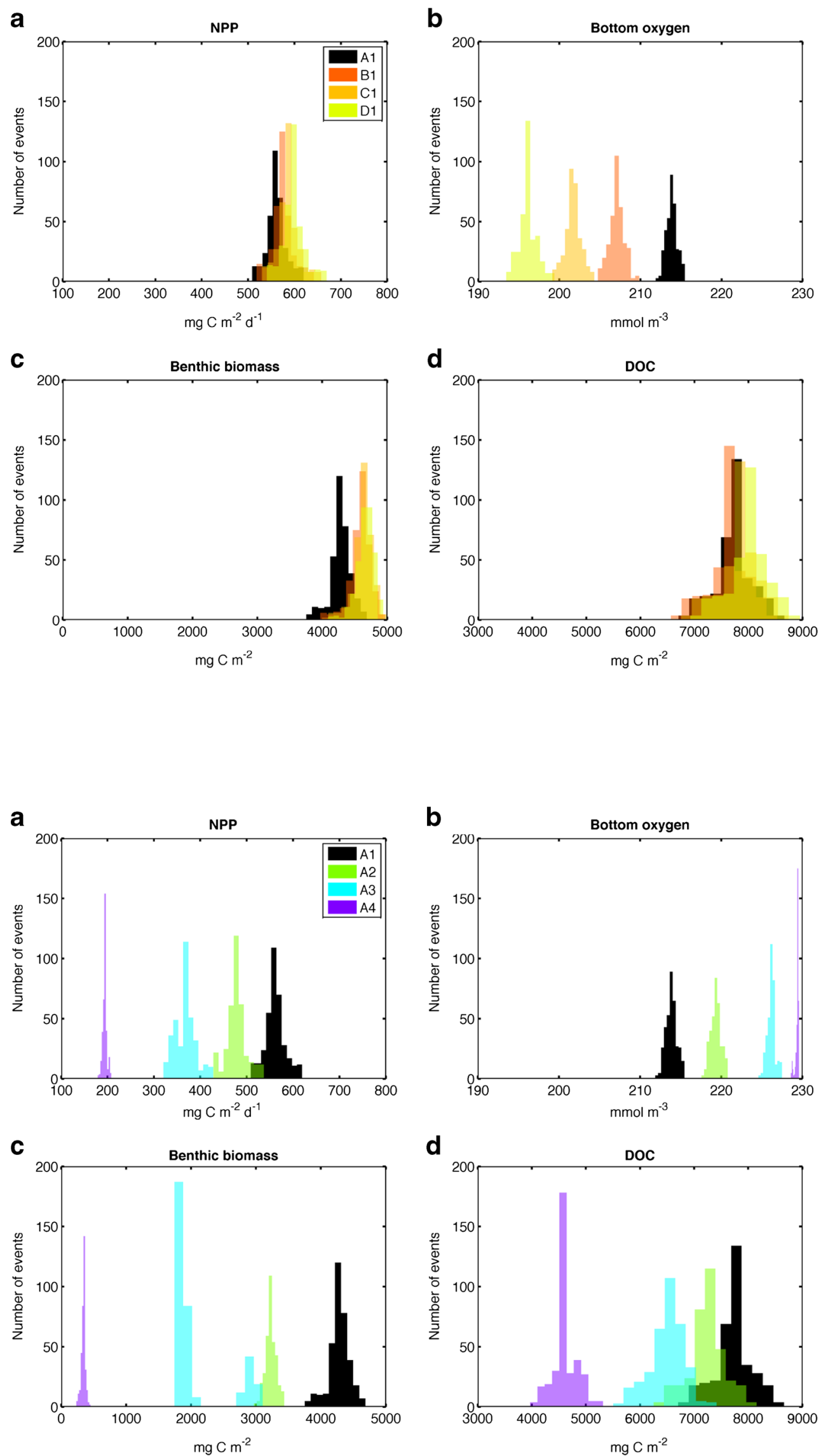
Fig. 10 Contour plot of the coefficient of variation (standard deviation normalised by the value of the respective ensemble mean). $X$ and $Y$ axis values and properties plotted as in Fig. 6
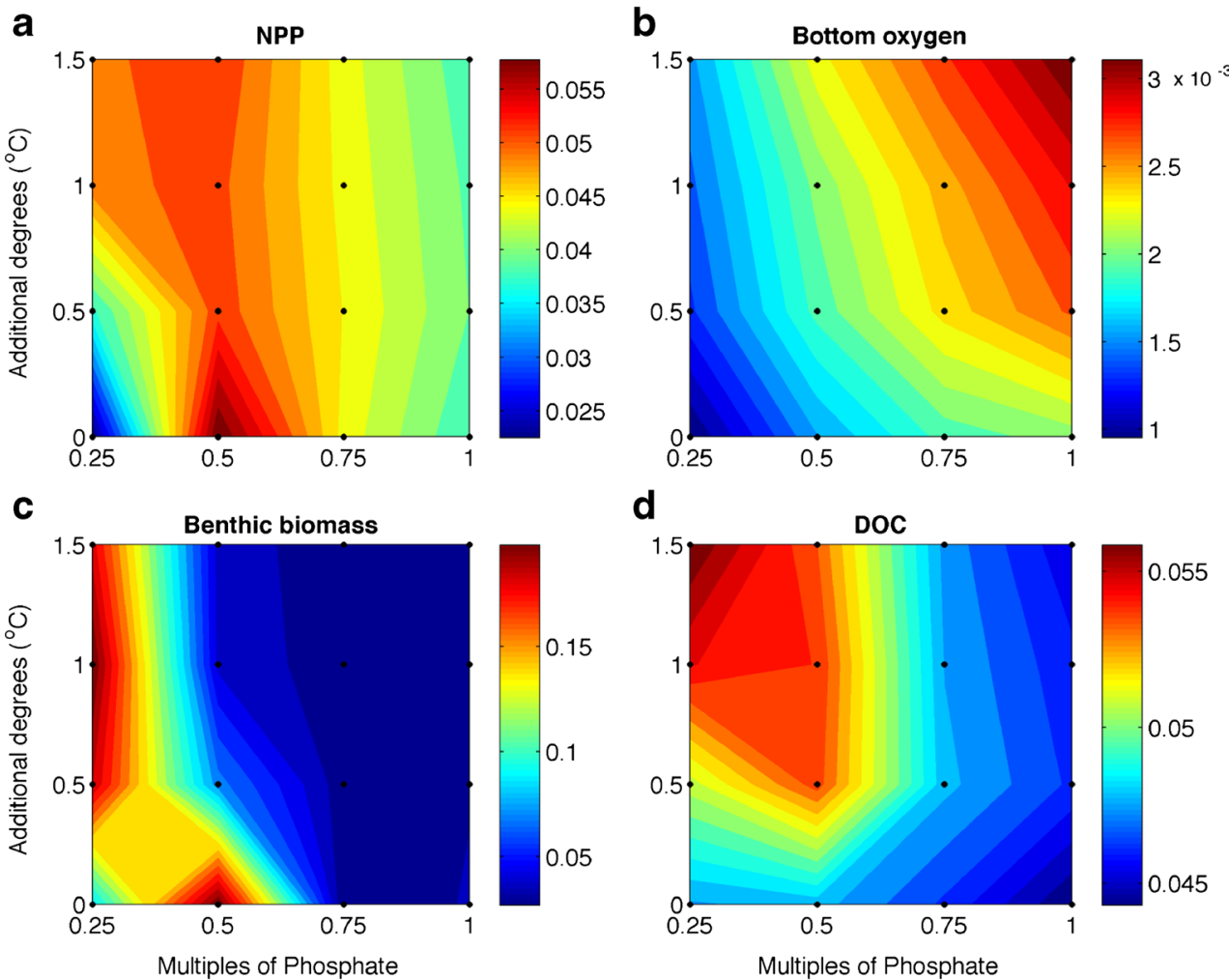

d

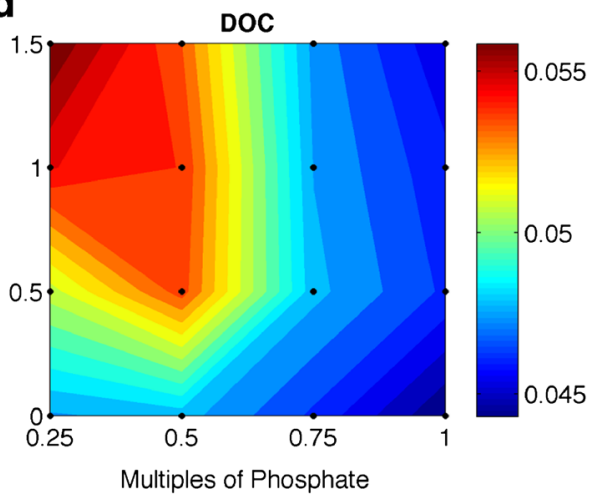

indicating that most of the changes are related to changes in the surface nutrient forcing with a reduced role of the temperature. This is similar to the ensemble mean variation of Fig. 7, but the uncertainty "peaks" in correspondence of an halving of the nutrient forcing with a somewhat mitigating effect of increasing temperatures.

It has already been stated above that the uncertainty variation affecting bottom oxygen (Fig. 10b) concentration can be considered as negligible, given the very low changes relative to the ensemble mean. The pattern of the oxygen concentration coefficient of variation is inversely related to the changes in concentration. However, the magnitude of the coefficient of variations is so small that it can be considered non-significant. The model projection for bottom oxygen concentration is then "robust" with respect to changes in model parameters in all scenarios.

The benthic biomass (Fig. 10c) experience the largest pattern of uncertainty variability. Maximum uncertainty occurs in general in correspondence of the lower biomass values (see Fig. 7) and under minimal surface load and higher temperature warming. The plot in Fig. 10c marks also a considerable uncertainty increase corresponding to a nutrient load halving under current temperature conditions.

Finally, the (relatively low) uncertainty of the DOC concentration in the control ensemble scenario increases as a function of the increasing temperature and the decreasing nutrient load. This indicates (for the DOC state variable) a progressive increase of the uncertainty for more stratified and oligotrophic trophic conditions, i.e. the system is progressively shifting towards a "microbial" food web system.

Since phosphate is the limiting nutrient in the Gulf of Trieste (Fonda Umani et al. 2007), a scenario of, for instance, increased climatic change (warming) and decreased anthropic input (external nutrient input) would be characterised by a decrease in NPP. This would then lead to a reduced DOC production and to a reduced overall benthic biomass (depending on the primary produced sinking organic matter). The uncertainty related to this pattern is then negligible for what concerns the bottom oxygen concentration, while for the other state variables and processes, it has different patterns of variation. However, all of them roughly point to an increase of the uncertainty corresponding to increased temperature and reduced nutrient load.

It has been stated above that each ensemble simulation is characterised by normal values distribution, with the only exception of the benthic biomass that, for the ensemble simulations characterised by a halving of the surface phosphate concentration and irrespective of the temperature change (see as an example Fig. 9c), gave a roughly bimodal distribution. This seems to be associated to the presence/absence of the filter feeder functional group (Mussap and Zavatarelli 2017).

Below a certain food source availability, their presence totally depends on the volume of water filtered, which is one of the parameters involved in the ensemble exercise 
(see Table 1). In fact, below a certain threshold imposed by both the phosphate concentration and the water volume filtered, this faunal group disappears determining a decrease in the total faunal concentration and the observed bimodal behaviour. When S1 and S2 are combined together to form scenario S3, results tend to organize into three clear groups with respect to the control ensemble (except for bottom oxygen). As previously seen, such organization is mainly determined by the phosphate surface concentration, given that a temperature increase does not cause large changes in the system. Moreover, as already seen in scenarios S1 and S2, the ensemble range (uncertainty) does not change much when temperature increases, while it reduces when surface phosphate decreases. For bottom oxygen, results are not clearly grouped like the other variables. The histograms of Fig. $11 \mathrm{~b}$ are the product of the two opposite reactions driven by the increase in temperature and the decrease in phosphate concentration. When surface phosphate concentrations are only slightly decreased (B2, C2, D2), it is temperature that defines the shift. In fact, means decrease in respect to A1, while ranges remain similar. Vice versa, when surface phosphate is strongly decreased (B4, C4, D4), it becomes the dominant factor in defining the changes in mean and range values. B2 and D3 fall closest to the control ensemble, showing a balance between the increase in temperature and the decrease in phosphate.

It can be preliminarily concluded then that the parameterrelated model uncertainties in predicting the state variable evolution under changing forcing scenarios is effectively scenario-depending. For the test cases investigated here, the most important change related to the scenarios adopted is the reduction in the nutrient load (rather than the warming). However, given the methodological example characteristics of the scenarios adopted, this result needs further confirmation by a more accurate definition of the current (and future) nutrient load in the area of implementation. Such variability

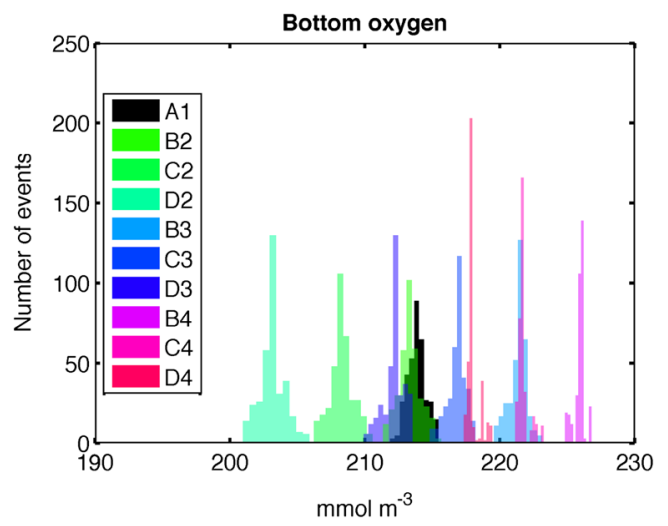

Fig. 11 Histograms of the bottom oxygen 352 members ensemble runs carried out for the S3 scenarios (+ control ensemble in black). Refer to Table 2 for information on the scenario associated to the ensemble number

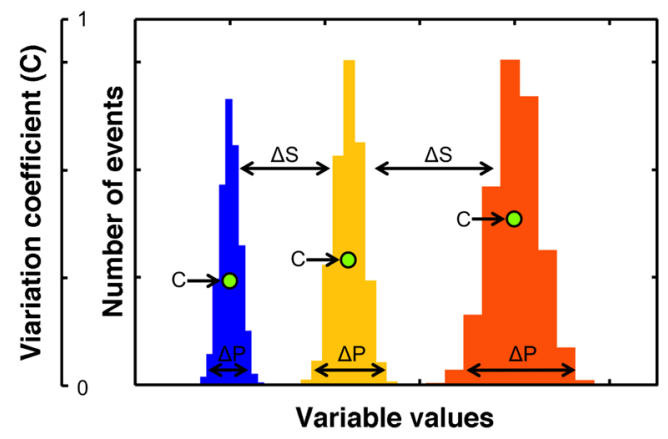

Fig. 12 Conceptual scheme of the strategy proposed to communicate effectively numerical modelling ensemble outputs to stakeholders under changing scenario conditions. Histograms representing ensembles are located in a $N-P$ space, where $N$ is the number of the events and $P$ is the state variable value. The second ordinate axis refers to the variation coefficient $(C)$ characterising each ensemble. $\Delta S$ indicates the shift of the ensemble mean due to the changing scenarios, while the ensemble range $(\Delta P)$ and the variation coefficient indicate for each ensemble the reliability of the model projection depending on the parameter choices

between scenarios is associated to a variability within the scenarios, characterised by a reduction of the model result uncertainties directly related to the nutrient load reduction. This seems to be associated to the general reduction in NPP that is impacting the whole biogeochemical system functioning towards a reduction in the parameter-related variability.

\section{Conclusions}

In this paper, we have shown results of a multi-parameter ensemble, multi-scenario exercise carried out with a coupled physical-biogeochemical 1D model designed for implementation in "data-rich" areas, i.e. areas interested by sustained monitoring of the hydrological properties. The parameter choice was based on low-level trophic variables that were considered to be important in defining system dynamics, but affected by considerable uncertainty because of poor observational evidence.

The purpose of this study was to assess the possible use of numerical models in contributing to the definition of EBM management plans, facing the possible direct or indirect (anthropogenically depending) changes in the forcing functions of the coastal ocean ecosystem.

To achieve the goal, the variability of the simulation results jointly determined by the variation in the forcing functions and by the model parameterisation was explored via an ensemble approach. In fact, a model-based prediction can support coastal management planning, aimed to achieve a "good environmental state", only with a sound estimation of the uncertainties associated to the scenario assumptions made and to the parameter choice, so that a "proactive" and 
not only a "reactive" (Green et al. 2009) management can be attempted. Recently, vulnerability and risk assessments for the coastal ocean based on comprehensive interdisciplinary three-dimensional modelling have been proposed (Rizzi et al. 2016). The numerical simulations at the base of such assessment adopt the scenario point of view to project into the future the long-term consequences of the climatic pressure on the coastal marine environment. It is believed that the insertion of the ensemble-based procedure described in this work into such assessment effort can greatly add value to the information originating from the simulation results, since it can provide, when including the assessment results into the formulation of an environmental management plan, an overall evaluation of the uncertainty associated to the simulation results, thereby enabling the policy maker and/or the environmental manager to evaluate with enhanced objectivity the possible consequences of the implementation of a specific management decision. Inserting this procedure into the wider effort proposed by Rizzi et al. (2016) would require a relatively minor effort: a one-dimensional version of the model used to simulate the coupled physical-biogeochemical dynamics, implemented at specific points (covered by observations) of the model domain, could be used to generate ensembles based on the joint variability of forcing functions and parameters. This would allow an overall evaluation of the uncertainty associated to the model parameterisation and the change in the pressures. As previously stated, such evaluation cannot be easily obtained in a fully three-dimensional model implementation due to the large number of simulations required to put together meaningful ensembles. The very high number of experiments carried out (352 runs for each of the 15 ensembles), that are allowed by the fast computational times of BFM-POM 1D, enabled to develop frequency distribution histograms allowing the observation of system shifts, and the evaluation of changes in the parameter-related uncertainty (Fiechter 2012). The choice of the analysed forcing function, state variables and impacted process adopted in this study is not exhaustive, but has shown that such approach is worthwhile to be attempted, since it has demonstrated that the uncertainty of the model predictions is closely associated not only to the chosen parameterisation, but also to the scenarios characteristics and that such changing variability effects (with different magnitude) state variables and impacted processes.

The scenario studies showed the potential impacts of climate change and environmental policy-related "pressures" (temperature and nutrient loading) affecting the coastal marine environment. Overall, the results of the ensemble simulations, carried out adopting a wide range of scenarios conditions (from minimal to extreme variations), showed that the system simulation uncertainties are crucially linked (as expected) to the model parameter choice, but also indicates that the uncertainty magnitude is strongly related to the changes in the ecosystem forcing (e.g. temperature and nutrient load). In fact, depending on the scenario, the parametrisation acquires or loses importance, increasing or decreasing uncertainty, as witnessed by the change in the ensemble standard deviation. This study is directed also towards the definition of an innovative and effective scientific communication between environmental scientists and stakeholders. Despite the (relative) simplicity of a onedimensional coupled biogeochemical model, the execution of an ensemble-based simulation experiment yields results that are both complicated, due to large number of runs, and complex, due to the interaction between the scenario forcing and the parameter set of variation (Hyder et al. 2015). In order to provide useful information for the development of environmental management plans and/or policies, the results must be conveyed to the interested stakeholders in an effective and comprehensible manner. The main aim is to effectively link numerical modelling to management issues and to provide an assessment of the inherent uncertainty affecting a numerical simulation. The conceptual scheme of the communication plan proposed is schematically shown in Fig. 12. Model results (frequency distribution from the ensemble runs) are presented via histograms located in an " $N-P$ and $N-C$ space", where $N$ is the number of events, $P$ is the state variable value and $C$ is the variation coefficient characterising each ensemble (see Fig. 10). The shift of the $P$ mean values $(\Delta S)$ is determined by the scenario assumptions with respect to the reference simulation, while the change in the ensemble standard deviation $(\Delta P)$, jointly with the variation coefficient value $(C)$, provide information about the projection uncertainty associated with the model parameters. The larger $\Delta P$ and $C$, the lower is the model robustness and the results reliability since the results have a large spread around the mean due to the parameter choices. The higher the shift of the $P$ mean value, the larger is the change in the overall system characteristics due to the scenario. On the other hand, the larger/smaller $\Delta P$, the larger/smaller is the uncertainty associated with the modelled scenario response. The proposed method does not define "good" or "bad" conditions, but represents results in a way that the interested stakeholder can independently evaluate the magnitude and the model reliability to project the marine food web changes in the future scenarios.

The proposed multi-parameter ensemble modelling strategy can be an effective support to the formulation of adaptive management strategies under combined pressures (Meier et al. 2014). This study aimed at exploring the potential numerical model contribution to EBM. We believe that the proposed new communication strategy can easily and effectively support stakeholders in the decision-making process, and we propose it for discussion to the scientific and stakeholder communities. 
Acknowledgements Giulia Mussap was financially supported by the Erasmus Mundus foundation [specific grant agreement number 2011-1614/001-001 EMJD] and the TESSA Project, and wishes to extend her sincere gratitude. The authors wish to thank Luca Giacomelli of the SiNCEM laboratory, University of Bologna (Ravenna), for the technical support. The support of the BFM system team is also acknowledged. The anonymous reviewers provided useful comments and criticisms, that greatly helped us to improve the manuscript.

Open Access This article is distributed under the terms of the Creative Commons Attribution 4.0 International License (http:// creativecommons.org/licenses/by/4.0/), which permits unrestricted use, distribution, and reproduction in any medium, provided you give appropriate credit to the original author(s) and the source, provide a link to the Creative Commons license, and indicate if changes were made.

\section{References}

Arkema KK, Abramson SC, Dewsbury BM (2006) Marine ecosystembased management: from characterization to implementation. Front Ecol Environ 4(10):525-532. https://doi.org/10.1890/15409295(2006)4[525:MEMFCT]2.0.CO;2

Artioli Y, Friedrich J, Gilbert AJ, McQuatters-Gollop A, Mee LD, Vermaat JE, Wulff F, Humborg C, Palmeri L, Pollehne F (2008) Nutrient budgets for european seas: a measure of the effectiveness of nutrient reduction policies. Mar Pollut Bull 56(9):1609-1617. https://doi.org/10.1016/j.marpolbul.2008.05.027. http://www. sciencedirect.com/science/article/pii/S0025326X08003172

Atkins JP, Burdon D, Elliott M, Gregory AJ (2011) Management of the marine environment: integrating ecosystem services and societal benefits with the DPSIR framework in a systems approach. Mar Pollut Bull 62(2):215-226

Baretta-Bekker J, Baretta J, WE (1997) Microbial dynamics in the marine ecosystem model ERSEM II with decoupled carbon assimilation and nutrient uptake. J Sea Res 38(3/4):195-212

Behrenfeld MJ, T O'Malley R, Siegel DA, McClain CR, Sarmiento JL, Feldman GC, Milligan AJ, Falkowski PG, Letelier RM, Boss ES (2006) Climate-driven trends in contemporary ocean productivity. Nature 444:752-755

Berrisford P, Dee D, Fielding K, Fuentes M, Kallberg P, Kobayashi S, Uppala S (2009) The ERA-Interim archive. Technical report. ECMWF, Shinfield Park, Reading. http://centaur.reading.ac.uk/ 1997/

Blumberg AF, Mellor GL (1987) A description of a three-dimensional coastal ocean circulation model. American Geophysical Union, $p$ 208. https://doi.org/10.1029/CO004p0001

Carniel S, Vichi M, Sclavo M (2007) Sensitivity of a coupled physicalbiological model to turbulence: high-frequency simulations in a northern adriatic station. Chem Ecol 23(2):157-175

Cloern J, Foster S, Kleckner A (2014) Phytoplankton primary production in the world's estuarine-coastal ecosystems. Biogeosciences 11:2477-2501

Coll M, Libralato S (2012) Contributions of food web modelling to the ecosystem approach to marine resource management in the mediterranean sea. Fish Fish 13(1):60-88. https://doi.org/10.1111/j. 1467-2979.2011.00420.x

Coma R, Ribes M, Serrano E, Salat J, Pascual J (2009) Global warming-enhanced stratification and mass mortality events in the Mediterranean. Proc Natl Acad Sci 14(15):6176-6181

Djakovac T, Degobbis D, Supic N, Precali R (2012) Marked reduction of eutrophication pressure in the northeastern adriatic in the period 2000-2009. Estuarine Coastal and Shelf Science 115:25-32
Droop M (1973) Some thoughts on nutrient assimilation in algae. J Phycol 9:264-272

Droop M (1975) The nutrient status of algal cells in batch cultures. Journal of the Marine Biology association of the United Kingdom $54: 825-855$

Dubovskaja O, Tang K, Gladyshev M, Kirillin G, Buseva Z, Kasprzak P, Tolomeev A, Grossart H (2014) Estimating in situ zooplankton non predation mortality in al oligo-mesotrophic lake from sediment trap data. Caveats and reality check. Plos one. https://doi.org/10.1371/journal.pone.0131431

Ebenhöh W, Kohlmeier C, Radford P (1995) The benthic biological submodel in the European Regional Seas Ecosystem Model. Neth J Sea Res 33(3-4):423-452. https://doi.org/10.1016/00777579(95)90056-X

Faganeli J, Ogrinc N (2009) Oxic-anoxic transition of benthic fluxes from the coastal marine environment (Gulf of Trieste, Northern Adriatic Sea). Mar Freshw Res 60:700-711

Faganeli J, Planinc R, Pezdic, Smodis B, Stegnar P, Ogorelec B (1991) Marine geology of the Gulf of Trieste (Northern Adriatic): Geochemical aspects. Mar Geol 99(1-2):93 108. https://doi.org/10.1016/0025-3227(91)90085-I. http://www. sciencedirect.com/science/article/pii/002532279190085I

Fagerbakke K, Heldal M, Norland S (1996) Content of carbon, nitrogen oxygen sulfur and phosphorus in native aquatic and cultured bacteria. Aquat Microb Ecol 10:15-27

Falkowski P, Barber R, Smetacek V (1998) Biogeochemical controls and feedbacks on ocean primary production. Science 281:200-206

Fiechter J (2012) Assessing marine ecosystem model properties from ensemble calculations. Ecol Model 242:164-179. https://doi.org/10.1016/j.ecolmodel.2012.05.016. http://www. sciencedirect.com/science/article/pii/S0304380012002372

Fonda Umani S (1996) Pelagic production and biomass in the Adriatic Sea. Sci Mar 60(2):65-77

Fonda Umani S, Del Negro P, Larato C, De Vittor C, Cabrini M, Celio M, Falconi C, Tamberlich F, Azam F (2007) Major inter-annual variations in microbial dynamics in the Gulf of Trieste (Northern Adriatic Sea) and their ecosystem implications. Aquat Microb Ecol 46(2):163-175

Gili J, Coma R (1998) Benthic suspension feeders: their paramount role in littoral marine food webs. Trends in Ecology and Evolution 13(8):316-321

Goldman JC, Caron DA, Dennett MR (1987) Regulation of gross growth efficiency and ammonium regeneration in bacteria by substrate C:N ratio. Limnol Oceanogr 32(6):1239-1252

Green D, Uccellini L, Colton M, Turner E, Scheurer D, Valette-Silver N, Matlock G, Brown C, Wilson D (2009) Toward a marine ecological forecasting system. In: OCEANS. IEEE, pp 1-6

Haney RL (1971) Surface thermal boundary condition for ocean circulation models. J Phys Oceanogr 1(4):241-248

Harley CD, Randall Hughes A, Hultgren KM, Miner BG, Sorte CJ, Thornber CS, Rodriguez LF, Tomanek L, Williams SL (2006) The impacts of climate change in coastal marine systems. Ecol Lett 9(2):228-241

Hirst A, Kiorboe T (2002) Mortality of marine planktonic copepods: global rates and patterns. Mar Ecol Prog Ser 230:195-209

Hoegh-Guldberg O, Bruno JF (2010) The impact of climate change on the world's marine ecosystems. Science 328(5985):1523-1528. https://doi.org/10.1126/science.1189930

Hyder K, Rossberg AG, Allen JI, Austen MC, Barciela RM, Bannister HJ, Blackwell PG, Blanchard JL, Burrows MT, Defriez E, Dorrington T, Edwards KP, Garcia-Carreras B, Heath MR, Hembury DJ, Heymans JJ, Holt J, Houle JE, Jennings S, Mackinson S, Malcolm SJ, McPike R, Mee L, Mills DK, Montgomery C, Pearson D, Pinnegar JK, Pollicino M, Popova EE, Rae L, Rogers SI, Speirs D, Spence MA, Thorpe R, Turner RK, van der Molen J, Yool A, Paterson DM (2015) Making modelling count-increasing the 
contribution of shelf-seas community and ecosystem models to policy development and management. Mar Policy 61:291-302

IPCC (2014) Climate change 2014: synthesis report. Contribution of Working Groups I, II and III to the Fifth Assessment Report of the Intergovernmental Panel on Climate Change

Krom M, Herut B, Mantoura R (2004) Nutrient budget for the Eastern Mediteranean: implications for phosphorus limitation. Limnol Oceanogr 49(5):1582-1592

Kujawinski E (2011) The impact of microbial metabolism on marine dissolved organic matter. Annual Reviews of Marine Sciences 3:567-599

Legendre L, Rassoulzadegan F (1995) Plankton and nutrient dynamics in marine waters. Ophelia 41(1):153-172. https://doi.org/10.1080/ 00785236.1995 .10422042

Ludwig W, Dumont E, Meybeck M, Heussner S (2009) River discharges of water and nutrients to the mediterranean and black sea: major drivers for ecosystem changes during past and future decades? Prog Oceanogr 80(3-4):199-217

Ludwig W, Bouwman A, Dumont E, Lespinas F (2010) Water and nutrient fluxes from major Mediterranean and Black Sea rivers: past and future trends and their implications for the basin-scale budgets. Glob Biogeochem Cycles 24(4):GB0A13. https://doi.org/10.1029/2009GB003,594

Mackenzie FT, Andersson A, Lerman A, May Ver L (2004) Boundary exchanges in the global coastal margin: implications for the organic and inorganic carbon cycles. In: The global coastal oceanmultiscale interdisciplinary processes, Harvard University Press, chap. 7, pp 193-225

Malacic V, Petelin B (2009) Climatic circulation in the Gulf of Trieste (Northern Adriatic). J. Geophys. Res. Oceans 114. https://doi.org/10.1029/2008JC004904

Marty JC, Chiaverini J, Pizay MD, Avril B (2002) Seasonal and interannual dynamics of nutrients and phytoplankton in the Western Mediterranean Sea at the DYFAMED time-series station (19911999). Deep Sea Research II(49):1965-1985

Meier HEM, Andersson HC, Arheimer B, Donnelly C, Eilola K, Gustafsson BG, Kotwicki L, Neset TS, Niiranen S, Piwowarczyk J, Savchuk OP, Schenk F, Wesławski JM, Zorita E (2014) Ensemble modeling of the Baltic Sea ecosystem to provide scenarios for management. AMBIO 43(1):37-48. https://doi.org/10.1007/ s13280-013-0475-6

Milliken FJ (1987) Three types of perceived uncertainty about the environment: state, effect, and response uncertainty. Acad Manag Rev 12(1):133-143

Mohlenberg F, Riisgard H (1979) Filtration rate using a new indirect technique in thirteen species of suspension feeding bivalves. Mar Biol 54:143-147

Mozetic P, Umani S, Cataletto B, Malej A (1998) Seasonal and inter-annual plankton variability in the Gulf of Trieste (Northern Adriatic). ICES J Mar Sci 55(4):711-722. https://doi.org/10.1006/ jmsc.1998.0396. ICES Symposium on Temporal Variability of Plankton and Their Physico-Chemical Environment, KIEL, GERMANY, MAR 19-21, 1997

Mussap G, Zavatarelli M (2017) A numerical study of the benthicpelagic coupling in a shallow shelf sea (Gulf of Trieste). Reg Stud Mar Sci 9:24-34. https://doi.org/10.1016/j.rsma.2016.11.002. http:// www.sciencedirect.com/science/article/pii/S2352485516301189

Mussap G, Zavatarelli M, Pinardi N, Celio M (2016) A management oriented 1-D ecosystem model: implementation in the Gulf of Trieste (Adriatic Sea). Regional Studies in Marine Science

Nyholm N (1977) Kinetics of phosphate limited algal growth. Biotech Bioeng 19:467-492
Oesterwind D, Rau A, AZ A (2016) Drivers and pressures-untangling the terms commonly used in marine science and policy. J Environ Manag 181:8-15

Officer C, Smayda T, Mann R (1982) Benthic filter feeding: a natural eutrophication control. Mar Ecol Prog Ser 9:203-210

Polimene L, Allen JI, Zavatarelli M (2006) Model of interactions between dissolved organic carbon and bacteria in marine systems. Aquat Microb Ecol 43(2):127-138. https://doi.org/10.3354/ame 043127

Rabalais N, Diaz R, Levin L, Turner R, Gilbert D, Zhang J (2010) Dynamics and distribution of natural and human caused coastal hypoxia. Biogeosciences 7:585-619

Rabalais N, Cai WJ, Carstensen J, Conley D, Fry B, Hu X, Slomp C, Turner R, Voss M, Wissel B, Zhang J (2014) Eutrophication-driven deoxygenation in the coastal ocean. Oceanography 27(1):172-183

Rapport D, Friend A (1979) Towards a comprehensive framework for environmental statistics: a stress-response approach, 1979, vol 11. Statistics Canada=statistique Canada

Ratto M, Castelletti A, Pagano A (2012) Emulation techniques for the reduction and sensitivity analysis of complex environmental models. Environ Model Softw 34:1-4

Ravetz JR (1986) Usable knowledge, usable ignorance: incomplete science with policy implications, chap. 15. Cambridge University Press. pp 415-432

Redfield AC (1934) On the proportions of organic derivatives in sea water and their relation to the composition of plankton. University Press of Liverpool James Johnstone memorial volume

Ricciardi A, Bourget E (1998) Weight to weight conversion factors for marine benthic macroivertebrates. Mar Ecol Prog Ser 163:245251

Rizzi J, Torresan S, Critto A, Zabeo A, Brigolin D, Carniel S, Pastres R, Marcomini A (2016) Climate change impacts on marine water quality: the case study of the Northern Adriatic Sea. Mar Pollut Bull 102:271-282

Robinson AR, Brink KH (2006) The global coastal ocean: interdisciplinary regional studies and syntheses, vol 14. Harvard University press

Ruardij P, Raaphorst WV (1995) Benthic nutrient regeneration in the \{ERSEM\} ecosystem model of the north sea. Neth J Sea Res 33(34):453-483. https://doi.org/10.1016/0077-7579(95)90057-8. http: //www.sciencedirect.com/science/article/pii/0077757995900578

Scavia D, Field J, Boesch DF, Buddemeier RW, Burkett V, Cayan DR, Fogarty M, Harwell MA, Howarth RW, Mason C, Reed DJ, Royer TC, Sallenger AS, Titus JG (2002) Climate change impacts on U.S. coastal and marine ecosystems. Estuaries 25(2):149-164

Schneider S (1990) The global warming debate heats up: an analysis and perspective. Bull Am Meteorol Soc 71(9):1292-1304

Slingo J, Palmer T (2011) Uncertainty in weather and climate prediction. Phil Trans R Soc 369:4751-4767

Slocombe DS (1993) Implementing ecosystem-based management: development of theory, practice, and research for planning and managing a region. Bioscience 43(9):612-622. https://doi.org/10.2307/1312148

Solidoro C, Bandelj V, Barbieri P, Cossarini G, Fonda Umani $S$ (2007) Understanding dynamic of biogeochemical properties in the Northern Adriatic Sea by using self-organizing maps and k-means clustering. J Geophys Res (Oceans) 112:C07S90. https://doi.org/10.1029/2006JC003553

Solidoro C, Bastianini M, Bandelj V, Cdermatz R, Cossarini G, Canu DM, Ravagnan E, Salon S, Trevisan S (2009) Current state, scales of variability and trends of biogeochemical properties in the Northern Adriatic Sea. J Geophys Res 114:C07S91. https://doi.org/10.1029/2008JC004,838 
Vichi M, Pinardi N, Zavatarelli M, Matteucci G, Marcaccio M, Bergamini M, Frascari F (1998a) One-dimensional ecosystem model tests in the Po Prodelta area (Northern Adriatic Sea). Environ Model Softw 13:471-481

Vichi M, Zavatarelli M, Pinardi N (1998b) Seasonal modulation of microbially mediated carbon fluxes in the Northern Adriatic Sea. Fish Oceanogr 7(3-4):182-190

Vichi M, Oddo P, Zavatarelli M, Coluccelli A, Coppini G, Celio M, Fonda-Umani S, Pinardi N (2003a) Calibration and validation of a one-dimensional complex marine biogeochemical flux modelin different areas of the Northern Adriatic Shelf. Ann Geophys 21(1):413-436

Vichi M, May W, Navarra A (2003b) Response of a complex ecosystem model of the Northern Adriatic Sea to a regional climate change scenario. Clim Res 24(2):141-159
Vichi M, Ruardij P, Baretta JW (2004) Link or sink: a modelling interpretation of the open Baltic biogeochemistry. Biogeosciences 1:79-100

Vichi M, Pinardi N, Masina S (2007) A generalized model of pelagic biogeochemistry.for the global ocean ecosystem. Part I: theory. J Mar Syst 64(1-4):89-109. https://doi.org/10.1016/j.jmarsys. 2006.03.006. Symposium on Advances in Marine Ecosystem Modelling Research, Plymouth, ENGLAND, JUN 27-29, 2005

Vrede T (1998) Elemental composition (C:N:P) and growth rates of bacteria and Rhodomonas frazed by Daphnia. J Plankton Res 20(3):455-470

Winter J (1978) A review of the knowledge of suspension feeding in lamellibranchiate bivalves, with special reference to artificial aquaculture systems. Aquaculture 13:1-33 